\title{
Basal Plus Basal-Bolus Approach in Type 2 Diabetes
}

\author{
F. Javier Ampudia-Blasco, M.D., ${ }^{1,2}$ Paolo Rossetti, M.D., ${ }^{1,3}$ and Juan F. Ascaso, M.D.,2
}

\begin{abstract}
Type 2 diabetes is characterized by insulin resistance and progressive $\beta$-cell deterioration. As $\beta$-cell function declines, most patients with type 2 diabetes treated with oral agents, in monotherapy or combination, will require insulin therapy. Addition of basal insulin (glargine, detemir, or NPH/neutral protamine lispro insulin) to previous treatment is accepted as the simplest way to start insulin therapy in those patients. But even when basal insulin is adequately titrated, some patients will also need prandial insulin to achieve or maintain individual glycemic targets over time. Starting with premixed insulin is an effective option, but it is frequently associated with increased hypoglycemia risk, fixed meal schedules, and weight gain. As an alternative, a novel approached known as "basal plus strategy" has been developed. This approach considers the addition of increasing injections of prandial insulin, beginning with the meal that has the major impact on postprandial glucose values. Finally, if this is not enough intensification to basal-bolus will be necessary. In reducing hyperglycemia, this modality still remains the most effective option, even in people with type 2 diabetes. This article will review the currently evidence on the basal plus strategy and also its progression to basal-bolus therapy. In addition, practical recommendations to start and adjust basal plus therapy will be provided.
\end{abstract}

\section{Introduction}

$\mathbf{T}$ YPE 2 DIABETES MELLITUS (T2DM) is characterized by insulin resistance and progressive $\beta$-cell deterioration, ultimately leading to a condition of insulin deficiency. ${ }^{1}$ As $\beta$-cell function declines, most patients with T2DM fail to maintain adequate metabolic control with oral agents (OAs) and will require insulin replacement over the time. ${ }^{2}$ Several clinical studies have shown that tight control of blood glucose levels in people with diabetes prevents the development and progression of the microvascular and macrovascular complications of diabetes. ${ }^{3-5}$ Therefore, when OAs as monotherapy or in combination are not enough to achieve or maintain invididual glycemic goals, addition of insulin is one of the most preferred therapeutic options for people with T2DM. ${ }^{6}$ Insulin is the most potent drug currently available to achieve tight glycemic control. However, it is not used frequently timely or aggressively enough to achieve the glycemic targets needed to prevent chronic complications. ${ }^{7}$

When insulin should be added, addition of basal insulin (BI) (glargine, detemir, or NPH/neutral protamine lispro [NPL] insulin) to previous OAs is accepted as the simplest way to start insulin therapy in people with T2DM. ${ }^{8-10}$ To be effective, BI needs to be titrated based on fasting self-monitoring of blood glucose (SMBG) (100-110 mg/dL [5.5-6.1 mmol/L]) when administered once daily or before dinner/bedtime ("Treat to
Target" concept). ${ }^{9,11}$ If a second injection of BI is necessary (detemir or NPH/NPL insulin), morning insulin dose should be also adjusted based on SMBG before dinner. ${ }^{12}$ This strategy has been successful bringing a significant proportion of patients (approximately 60-70\%) to target, ${ }^{9,10}$ at least during the first 612 months, or even up to $2-3$ years. ${ }^{13}$ However, a remaining important proportion of patients will need prandial insulin to achieve or maintain glycemic objectives. Alternatively, recent studies suggest that adding glucagon-like receptor-1 receptor agonists or dipetidyl peptidase- 4 inhibitors to BI may be also effective and safe in this context, ${ }^{14,15}$ considering that some patients may still retain enough pancreatic reserve.

Adding prandial insulin only (without $\mathrm{BI}$ ) has been proposed as another alternative to start insulin when failing OAs in patients with T2DM. In terms of reduction of $\mathrm{A}_{1 \mathrm{C}}$, such a strategy is as effective ${ }^{16}$ or even better ${ }^{17}$ than starting insulin therapy with BI and achieves a superior postprandial control. ${ }^{16,18}$ However, this approach does not seem to result into better cardiovascular outcomes in high cardiovascular risk T2DM patients. ${ }^{18}$ Furthermore, the addition of prandial insulin results in a greater incidence of hypoglycemia, ${ }^{16,17}$ even when $\mathrm{BI}$ is successfully titrated to obtain comparable $\mathrm{A}_{1 \mathrm{C}}$ levels. ${ }^{16}$ For these reasons, when insulin is needed, BI is considered the preferred starting option.

Therefore, progressing in insulin therapy needs a combination of basal and prandial insulin. Between the different

\footnotetext{
${ }^{1}$ Diabetes Reference Unit, Endocrinology and Nutrition Department, Clinic University Hospital of Valencia, Valencia, Spain.

${ }^{2}$ Department of Medicine, University of Valencia, Valencia, Spain.

${ }^{3}$ Automatism and Industrial Informatic's Institute, Polytechnic University of Valencia, Valencia, Spain.
} 
therapeutic options, starting with premixed insulin twice or three times daily is one of the most widely used options. ${ }^{19}$ Premixed insulin-based therapy, although effective in reducing hyperglycemia, is frequently associated with an increased risk of hypoglycemia, a need of fixed meal schedules, and weight gain. ${ }^{20,21}$ As an alternative to premixed insulin, basalbolus therapy (or multiple daily injections) still remains as the most effective insulin strategy, even in people with T2DM. ${ }^{22,23}$ Because this option is rarely accepted by patients, at least initially, other options have been searched to facilitate a stepwise intensification of insulin therapy in people with T2DM when progressive deterioration of $\beta$-cell function is inevitable. Recently, a new therapeutic option, known as "basal plus strategy," has been evaluated in these patients when $\mathrm{BI}$ in combination with OAs is not longer enough to achieve glycemic goals. $^{24}$

This article will review the currently evidence on the basal plus strategy and also its progression to basal-bolus therapy (Fig. 1). In addition, practical recommendations to start and adjust basal plus therapy will be provided.

\section{“Basal Plus" Therapy}

The concept of basal plus considers the addition of increasing injections of prandial insulin, beginning with the meal that has the major impact on postprandial glucose values, and maintaining previous treatment with BI and OAs. ${ }^{25}$ As explained below, this represents an effective strategy for a "soft" transition to the more physiologic (and effective) replacement of insulin by means of classical basal-bolus therapy. ${ }^{24}$

\section{When to move from basal to basal plus}

Patients eligible to start basal plus therapy are those treated with basal therapy with or without $\mathrm{OAs}$ who do not reach $\mathrm{A}_{1 \mathrm{C}}$ goals ( $<7.0 \%$ for most patients), even after adequate titration of BI to target (100-110 mg/dL [5.5-6.1 mmol/L]) ${ }^{25}$ In addition, it has been suggested that also patients using high doses of BI without success $(>0.7 \mathrm{U} . / \mathrm{kg})$ or who had limitations on increasing BI doses because of high risk of nocturnal hypoglycemia are good candidates. ${ }^{26}$ Although evidence is scarce, other patients may potentially profit of basal plus therapy, as suggested by a recent experts' document, summarized in Table $1 .^{26}$

Most patients will have a slightly elevated $\mathrm{A}_{1 \mathrm{C}}$ (between $7.0 \%$ and $8.0 \%$ ). Indeed, Monnier et al. ${ }^{27}$ have suggested that excessive postprandial glucose excursions are the most important component of hyperglycemia for patients with less elevated $\mathrm{A}_{1 \mathrm{c}}$ levels $(\sim 7.3 \%)$. In addition, using continuous glucose monitoring it has been demonstrated that high postprandial glucose levels are the first recognized glucose abnormality, especially after breakfast, even before fasting glucose values deteriorates. ${ }^{28}$ Recently, it has been reported that the relative contribution of postprandial hyperglycemia increases to approximately $60 \%$ for an $\mathrm{A}_{1 \mathrm{C}}$ below $8 \%$, independent of the $A_{1 C}$ ranges, but only when $\mathrm{BI}$ is titrated appropriately. ${ }^{29}$ In any case, it seems reasonable to suggest that when patients are closed to the $\mathrm{A}_{1 \mathrm{C}}$ target the addition of a fitting dose of prandial insulin administered at the main meal might be effective.

\section{Review of the current evidence}

Because the basal plus strategy is a relatively new concept coming out in the last years, only a few trials have been published until now. In the "Proof Of Concept" (POC) trial, 106 patients with $\mathrm{T} 2 \mathrm{DM}$ treated with insulin glargine in combination with $\mathrm{OAs}$ and $\mathrm{A}_{1 \mathrm{C}}>7.0 \%$ (60\% women; age $\left[\right.$ mean $\pm \mathrm{SD}$ ], $60 \pm 8$ years; body mass index, $33.3 \pm 4.8 \mathrm{~kg} / \mathrm{m}^{2}$; $\mathrm{A}_{1 \mathrm{C}}, 7.9 \pm 0.6 \%$; fasting plasma glucose, $111 \pm 22 \mathrm{mg} / \mathrm{dL}$ ) were randomized to continue with the same treatment (control group) or to the addition of insulin glulisine before the main meal (intervention group). ${ }^{30}$ After 3 months, patients assigned to the glulisine group $(0.14 \pm 0.07 \mathrm{U} / \mathrm{kg} /$ day $)$ achieved a greater reduction of $\mathrm{A}_{1 \mathrm{C}}(-0.36$ vs. $-0.13 \%$ in the control group, $P=0.029$ ), without a significant increase of hypoglycemic episodes. BI increased in the control group from $0.59 \pm 0.26$ to $0.65 \pm 0.32 \mathrm{U} / \mathrm{kg} /$ day (no statistical value reported), but not in the glulisine group (from $0.57 \pm 0.31$ to

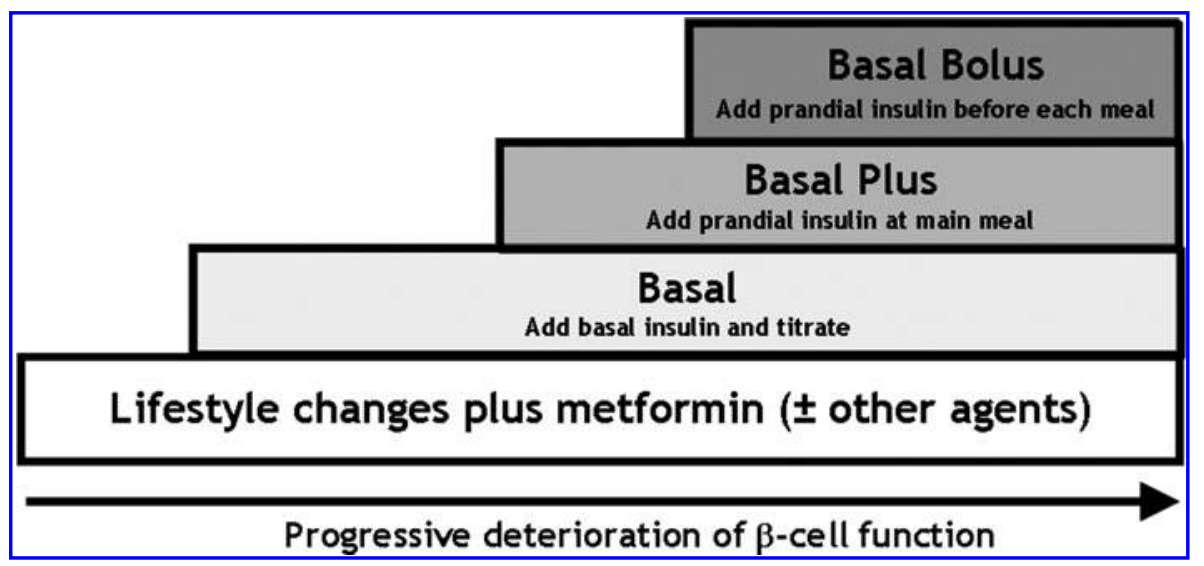

FIG. 1. Matching treatment to disease progression in type 2 diabetes mellitus using a stepwise approach. Adapted from Raccah et al. ${ }^{24}$ Type 2 diabetes is a progressive disease marked by insulin resistance and increasing failure of the pancreatic $\beta$-cell function. Therefore, as diabetes progresses, treatment will need to be intensified, including addition of insulin. Starting basal insulin in addition to previous oral agents is the simplest way to initiate insulin therapy in people with type 2 diabetes. When $\beta$-cell dysfunction progresses, prandial insulin is necessary and may be given using different strategies (see text). The progression from basal therapy to basal plus, and then to basal-bolus therapy, is shown schematically. 
Table 1. Selection of an Appropriate Candidate for Insulin Intensification with Basal Plus Therapy

Clinical situations

Patients on basal insulin \pm oral agents with an $\mathrm{A}_{1 \mathrm{C}}$ between $7.0 \%$ and $8.0 \%$

Patients treated with 2 or 3 oral agents and a high $\mathrm{A}_{1 \mathrm{C}}>8.5-9.0 \%$

Patients on basal insulin \pm oral agents with an $\mathrm{A}_{1 \mathrm{C}}>8 \%$ who are reluctant to start basal bolus therapy

Patients previously treated with premixed insulin twice daily

Patients starting corticoid therapy for other concomitant diseases
Comments

Ideal candidates. A high percentage will achieve an $\mathrm{A}_{1 \mathrm{C}} \leq 7 \%$.

After optimized titration of basal insulin, addition of increasing injections of prandial insulin will be necessary to reach an $\mathrm{A}_{1 \mathrm{C}} \leq 7 \%$.

Basal plus should be considered as a transitional therapy to progress steeply to basal-bolus therapy, which will be necessary for most patients in this clinical situation.

For those with frequent hypoglycemia episodes and/or irregular glycemic profiles, basal plus will offer an alternative.

May be a valuable alternative to achieve stable daily glycemic profiles, especially at lunch and dinner

Modified from Merchante et al. ${ }^{26}$

$0.59 \pm 0.35 \mathrm{U} / \mathrm{kg} /$ day). In addition, in the intervention group a higher proportion of patients reached an $\mathrm{A}_{1 \mathrm{C}}<7.0 \%(22 \%$ vs. $9 \%$ in the control group). This POC study confirmed that the addition of only one injection of prandial insulin may reduce further $\mathrm{A}_{1 \mathrm{C}}$ by approximately $0.3-0.4 \%$ without increasing the risk of hypoglycemia.

In the "Oral Plus Apidra and Lantus" (OPAL) trial, 393 patients with T2DM receiving treatment with insulin glargine and OAs and insufficient glycemic control (mean basal $\mathrm{A}_{1 \mathrm{C}}$ was $\sim 7.4 \%$ ) were randomized to the addition of insulin glulisine before breakfast or before the main meal. ${ }^{31}$ The main meal was defined as the meal associated with the highest postprandial glycemic excursion based on several daily glycemic profiles. The initial dose of insulin glulisine $(\sim 5 \mathrm{U})$ was individually increased in both groups, at the discretion of the investigators, using a similar target of 2-h postprandial glucose values for titration $(\leq 135 \mathrm{mg} / \mathrm{dL}[\leq 5.5 \mathrm{mmol} / \mathrm{L}])$. After 24 weeks, $\mathrm{A}_{1 \mathrm{C}}$ was reduced similarly $\sim 0.4 \%$ in both groups using similar doses of insulin glulisine $(\sim 11 \mathrm{U})$, although a greater proportion of patients reached the goal of $\mathrm{A}_{1 \mathrm{C}}<7.0 \%$ in the main meal group (52\% vs. $37 \%$ in the breakfast group). No differences in the frequency of hypoglycemias were found between the groups $(\sim 2.52$ hypoglycemic events per patient per year). Body weight increased similarly about $\sim 1 \mathrm{~kg}$ in both groups.

In the "Optimisation of Insulin Treatment of Type 2 Diabetes Mellitus by Telecare Assistance for Self Monitoring of Blood Glucose" (ELEONOR trial), 200 patients failing on one or more OAs ( $54 \%$ men; age, $58.9 \pm 8.2$ years; body mass index, $29.9 \pm 4.3 \mathrm{~kg} / \mathrm{m}^{2}$; duration of diabetes, $10.9 \pm 6.9$ years; basal $\mathrm{A}_{1 \mathrm{C}}, 8.9 \pm 0.9 \%$ ) were randomized to insulin dose adjustment by either electronic transfer of capillary blood glucose readings (Telecare program) or standard SMBG (control group). ${ }^{32}$ After an initial phase of $8-16$ weeks, in which insulin glargine was optimized to achieve fasting blood glucose $\leq 100 \mathrm{mg} / \mathrm{dL}(5.5 \mathrm{mmol} / \mathrm{L})$, patients were randomized to glulisine once daily, at the main meal, for an additional 24 weeks. Insulin glulisine adjustments in the follow-up were based on postprandial glucose measurements (target, 100$140 \mathrm{mg} / \mathrm{dL}$ ) using also Telecare or SMBG. Mean $\mathrm{A}_{1 \mathrm{C}}$ decreased similarly from baseline to end point $(8.8 \%$ to $7.1 \%$ for Telecare; $8.9 \%$ to $7.0 \%$ for SMBG). The single injection of glulisine was responsible for the last $0.7-0.8 \%$ decrement (both $P<0.0001$ vs. with glargine alone). The proportion with
$\mathrm{A}_{1 \mathrm{C}} \leq 7.0 \%$ at end point did not differ significantly between the Telecare and SMBG groups (50.6\% vs. 54.6\%). There was no difference in weight changes (Telecare vs. SMBG, $+0.4 \pm 3.0$ vs. $+0.1 \pm 5.0 \mathrm{~kg}$ ), glargine final dose ( $29 \pm 16$ vs. $28 \pm 17 \mathrm{U} /$ day), or glulisine final dose $(8.3 \pm 7.1$ vs. $8.1 \pm 8.1 \mathrm{U} /$ day). Severe hypoglycemia episodes were experienced by three subjects in the Telecare group and one patient in the SMBG group. In this study, the efficacy of basal plus strategy was unaffected by the insulin dose adjustment method used.

The 1-2-3 trial was designed to evaluate the effectiveness of the increasing addition of prandial insulin injections in patients with T2DM previously treated during a 14-week run-in period with $\mathrm{BI}$ and OAs and having bad metabolic control. ${ }^{33}$ Thereafter, 343 patients (age, 53 years; body mass index, $37 \mathrm{~kg} / \mathrm{m}^{2} ; \mathrm{A}_{1 \mathrm{C}}, 7.9 \%$; fasting plasma glucose, $120 \mathrm{mg} / \mathrm{dL}$; duration of diabetes, 10 years) were randomized to three groups depending of the number of injections of insulin glulisine administered before the main meal. After 24 weeks, $\mathrm{A}_{1 \mathrm{C}}$ values were reduced similarly in all groups $(-0.46 \%$ vs. $-0.46 \%$ vs. $-0.58 \%$ in the group with one, two, or three additional injections of insulin glulisine, respectively). However, the proportion of patients achieving an $\mathrm{A}_{1 \mathrm{C}} \leq 7.0 \%$ was higher with increasing number of injections (30\% vs. $33 \%$ vs. $45 \%$ with one, two, or three injections of insulin glulisine, respectively). In addition, the hypoglycemia rate increased with the rising number of glulisine injections $(0.10$ vs. 0.30 vs. 0.26 events/patient/year with one, two, or three injections, respectively), although only significantly higher when comparing the group with one versus two shots of insulin glulisine $(P=0.043)$.

Recently, two additional trials have been reported evaluating the efficacy and safety of the stepwise intensification of prandial insulin. In one trial, 296 patients with T2DM and not controlled with insulin detemir and OAs (mean values: age, 58.3 years; $\mathrm{A}_{1 \mathrm{C}}$, $8.8 \%$; duration of diabetes, 12.3 years) were randomized to stepwise addition of insulin aspart in the largest perceived meal $(n=150)$ or in the meal with the largest postprandial glucose increment $(n=146) .{ }^{34}$ After a run-in period, in which basal doses were optimized, patients received increasing doses of insulin aspart after 12-week periods if $A_{1 C}$ was $\geq 7 \%$ according to the different protocols. Sulfonylureas were discontinued before randomization. Both strategies were equally effective in reducing $\mathrm{A}_{1 \mathrm{C}}$ by $\sim 1.2 \%$ 
(by $\sim 0.5 \%$ in period 1 , by a further $\sim 0.5 \%$ in period 2 , and by $\sim 0.2 \%$ in period 3 in both groups). The overall rate of hypoglycemia was low, and weight gain was comparable, between 2.0 and $2.7 \mathrm{~kg}$, at the end of the trial.

In the other trial, stepwise addition of prandial insulin with or without discontinuation of sulfonylureas was compared with the basal-bolus therapy in patients with type 2 diabetes. ${ }^{35}$ After a 6-month period in which insulin glargine was optimized ( $36 \mathrm{U} /$ day; mean $\mathrm{A}_{1 \mathrm{C}}, 8.3 \%$ ), patients with $\mathrm{A}_{1 \mathrm{C}}>7 \%$ and fasting plasma glucose $<6.7 \mathrm{mmol} / \mathrm{L}$ $(<120 \mathrm{mg} / \mathrm{dL})(n=476)$ were then randomized to the three different strategies. All patients received insulin glulisine as prandial insulin, which was titrated according to postprandial values. Increasing doses of insulin glulisine were added at 4month intervals upon the next meal with the highest postprandial glucose value. After 1 year, full basal-bolus therapy was not superior to stepwise intensification of prandial insulin, without or with sulfonylureas (change of $\mathrm{A}_{1 \mathrm{C}},-0.72 \%$ vs. $-0.47 \%$ vs. $-0.40 \%$, respectively; prespecified margin of non-inferiority, $\leq 0.4 \%$ ). Mean glulisine dose at end point was 29,20 , and $17 \mathrm{U} /$ day, respectively, with $33 \%$ and $40 \%$ of patients remaining on one glulisine injection in the group without or with sulfonylureas. The incidence of symptomatic hypoglycemia was highest with sulfonyluresa and lowest without (between-group differences were not significant). Weight gain was also significantly lower in the group with stepwise addition of prandial insulin without sulfonylureas compared with the basal-bolus group $(+1.30 \mathrm{vs} .+2.03 \mathrm{~kg}$, $P<0.05)$.

In summary, although the current evidence is still scarce and the designs of the different trials were heterogeneous, the addition of increasing number of prandial insulin injections seems to be an effective and safe treatment modality. Therefore, the basal plus strategy should be view as an alternative for those patients treated with BI and OAs who are not able to achieve or maintain their individual glycemic goals. ${ }^{36}$
Recently, this concept has been also incorporated in the treatment algorithm supported by a group of experts from the European Association for the Study of Diabetes and the American Diabetes Association. ${ }^{11}$ However, the currently algorithm is sparse regarding how to initiate, titrate, and intensify prandial insulin doses.

\section{Practical issues regarding basal plus strategy}

How to initiate and titrate prandial insulin. In the basal plus strategy, the initial dose of prandial insulin can be calculated using different methods, although all of them offer similar results (Table 2). To start, you can use a fixed dose or find an individual dose depending on weight, previous BI dose, or currently postprandial glucose values. Initiating with a very small fixed dose is the simplest way to add prandial insulin and avoid hypoglycemia, although this dose may be very low depending on the patient. In any case, each healthcare provider should try one of the offered possibilities or search for an alternative.

Finding the most appropriate dose of prandial insulin safely requires using an adequate titration algorithm and defining the most valuable glucose target. Insulin doses may be adjusted based on either preprandial or postprandial glucose values. Some guidelines recommend achieving a 2-h postprandial glucose value lower than $140 \mathrm{mg} / \mathrm{dL}$ $(7.8 \mathrm{mmol} / \mathrm{L}),{ }^{37,38}$ which in many cases means limiting the glucose excursion to less than $40-50 \mathrm{mg} / \mathrm{dL}(2.2-2.8 \mathrm{mmol} /$ L). ${ }^{39}$ In the case of using rapid-acting insulin analogs (RAIAs), adjustments based on postprandial glucose values seem to be more worthwhile.

Increasing the dose of prandial insulin can be performed with fixed dose increments (i.e., 1 or more units each time) or depending of the previous prandial insulin dose or level of postprandial glucose values (see Table 2). Titration should be performed regularly based on SMBG. Patients should be in-

Table 2. Starting Prandial Insulin Dose and Adjustments Algorithm

Initiation dose of prandial insulin

Methods Initial dose

Fixed initial dose ${ }^{21}$

Based on level of postprandial glucose values ${ }^{20}$

Based on patient's weight ${ }^{26}$

Based on previous basal insulin dose ${ }^{27}$
$4 \mathrm{U}$

Glucose values $(\mathrm{mmol} / \mathrm{L}) / 2(1 \mathrm{mmol} / \mathrm{L}=18 \mathrm{mg} / \mathrm{dL})$

$0.05 \mathrm{U} / \mathrm{kg}$

$10 \%$ of basal insulin dose
Adjustment algorithm

Methods

Fixed-increments based on postprandial glucose values above $\operatorname{target}^{21}$

Based on postprandial glucose values ${ }^{20}$

Based on previous prandial insulin dose if postprandial glucose values are above target $^{27}$

\section{Recommendations}

Postprandial glucose value $>140 \mathrm{mg} / \mathrm{dL}$ : increase $+1 \mathrm{U}$

Between 136 and $153 \mathrm{mg} / \mathrm{dL}$ : increase $+1 \mathrm{U}$ Between 154 and $180 \mathrm{mg} / \mathrm{dL}$ : increase $+2 \mathrm{U}$ $>180 \mathrm{mg} / \mathrm{dL}$ : increase $+3 \mathrm{U}$

Dose $\leq 10 \mathrm{U}$ : increase $+1 \mathrm{U}$

Dose 11-20 U: increase $+2 \mathrm{U}$

Dose $>20 \mathrm{U}$ : increase $+3 \mathrm{U}$

The frequency of dose adjustments should be individualized, but changes can be done every 3 days or weekly. Patients should be trained in self-dose adjustments. 
structed to be able to implement titration algorithms at home. Changing insulin doses when necessary every 3 days or weekly seems to be reasonable.

Selection of the prandial insulin to be used will depend on the patient's characteristics, availability of insulin, and costs. RAIAs (lispro, aspart, glulisine) have to be administered with the meals and try to reproduce the rapid, potent, and shortacting insulin-secretory response that takes place with endogenous insulin after intake in individuals without diabetes. Compared with regular insulin, RAIAs reduce postprandial glycemic excursions more effectively, as well as the incidence of late hypoglycemia (before the next intake). ${ }^{40}$ Moreover, because of their rapid action, RAIAs may be administered just before the meal or even after, which is particularly appreciated by some patients, in particular, by elderly persons with unpredictable intake. In contrast, regular insulin requires administration $30-45 \mathrm{~min}$ before the meals, which in fact rarely is accomplished by patients on a daily basis.

Finally, when basal plus therapy is implemented no changes in previous BI dose are necessary. However, it seems logical to avoid nocturnal hypoglycemias, reducing the dose of BI by $\sim 10 \%$ if the selected main meal to start with prandial insulin is the dinner. ${ }^{26}$

Recommendations about the use of OAs in the basal plus concept. In general, OAs used in combination with BI should be maintained also in the basal plus strategy. Metformin should be continued and is beneficial in association with insulin, irrespective of the insulin regimen. In relation to glitazones (only currently pioglitazone is available in Europe), although these agents may have potential benefits in some patients, it seems prudent to avoid their combination with insulin because of the potential for increased fluid retention and weight gain. Other OAs such as sulfonylureas, glinides, or dipeptidyl peptidase-4 inhibitors (sitagliptin) may be maintained during basal plus. A recent study compared continuation versus discontinuation of insulin secretagogues (sulfonylureas and glinides) in addition to metformin when initiating $\mathrm{BI}$ in patients with T2DM over 24 weeks. ${ }^{41} \mathrm{~A}_{1 \mathrm{C}}$ reduction was similar in both groups (continuing vs. stopping secretagogues, $-1.59 \%$ vs. $-1.30 \%, P=0.382$ ). However, in patients continuing insulin secretagogues, although lower BI doses were necessary, a higher hypoglycemia rate $(40.0 \%$ vs. $24.5 \%$ with at least one symptomatic hypoglycemic event, $P<0.001)$ and an increased weight gain $(+1.44$ vs. $+0.43 \mathrm{~kg}$, $P<0.001$ ) were found. Conversely, stopping these agents at initiation of basal plus therapy may result in a significant increase of insulin doses. ${ }^{26}$ In any case, when increasing prandial insulin injections are needed, which may suggest a more important deterioration of $\beta$-cell function, it will be advisable to suspend treatment with sulfonylureas or glinides, and probably also with dipeptidyl peptidase- 4 inhibitors. ${ }^{42}$

Other aspects. In relation to how many and how often patients should perform SMBG when transferring to basal plus therapy, there are no well-established recommendations. At the start, to identify the main meal, it will be necessary to recollect at least two or three daily glycemic profiles, including preprandial and 2-h postprandial glucose values after breakfast, lunch, and dinner. These procedures should be repeated when increasing prandial insulin injections are needed in order to identify the next main meal.
Regarding the titration process, prandial insulin doses should be adjusted taking into consideration postprandial (preferable) and preprandial (before the next meal) glucose values. Therefore, in addition to monitor fasting blood glucose to adjust prospectively BI doses, daily monitoring of postprandial glucose values at least after the main meal is important initially. If RAIAs are used, this practice is even more important, and postprandial values remain the best in the dosing process. When glucose values are stable, how many times and how often SMBG should be performed by patients should be established based on an individual basis.

Instructing patients on carbohydrate counting may be advisable in some patients and can be very effective when used in the context of a structured insulin dosing algorithm, ${ }^{22}$ but in general this is not necessary and should not be implemented in patients with T2DM transferred to the basal plus strategy.

\section{Transition to Basal-Bolus Approach}

As commented on before, in clinical practice, the basal plus strategy is acceptable for many patients. When $\beta$-cell dysfunction deteriorates further and more complicated insulin regimens are needed, this therapeutic alternative may facilitate moving from the previous strategy of BI combined with OAs, which is easier, to the basal-bolus therapy. ${ }^{43}$ Although addition of a BI to OAs allows approximately $60-70 \%$ of insulin-naive patients to achieve the goal of $A_{1 C}<7 \%, 9,10,12$ data from the United Kingdom Prospective Diabetes Study and Kumamoto studies clearly demonstrated that for most patients attainment of glycemic goals requires early intensification of insulin therapy with the addition of prandial insulin to basal. ${ }^{4,5,44,45}$ This concept has been recently confirmed in the 3-year follow-up of the 4-T trial. ${ }^{46}$ However, the choice between a basal-prandial and a premixed "biphasic" insulin regimen, as well as the use of analogs instead of human insulins, is a matter of debate.

\section{Basal-bolus versus premixed insulins}

When the intensification of hypoglycemic treatment is needed, the use of prandial premixed insulin is an effective option with a mean reduction in $\mathrm{A}_{1 \mathrm{C}}$ of about $1.2-1.5 \%{ }^{23,47}$ and $45-50 \%$ of patients achieving an $\mathrm{A}_{1 \mathrm{C}}<7 \%$. ${ }^{48}$ In comparison, the use of a basal-bolus strategy (four or five injections per day) is associated with a slightly greater reduction in $\mathrm{A}_{1 \mathrm{C}}$ (about $1.5-1.8 \%$ ) and a greater proportion of patients achieving $\mathrm{A}_{1 \mathrm{C}}<7 \%(50-55 \%){ }^{22,23,49,50}$ The high efficacy of basal-bolus therapy in T2DM has been proven in the study from Bergenstal et al. ${ }^{22}$ Here, a population of insulin-treated (36\% premixed, $37 \%$ glargine plus one or more shots of rapidacting insulin, 27\% various other regimens) obese T2DM patients was switched to basal-bolus and randomized to two different algorithms for prandial insulin titration. Independent of the mealtime insulin dose adjustment strategy, $70-75 \%$ of subjects reached the goal of $A_{1 C}<7 \%$, with a mean reduction from baseline of about $1.5 \%$ in both groups. In the very few direct comparisons between the premixed and basal-bolus regimens, ${ }^{23,50,51}$ the latter resulted in a greater proportion of patients in target (mean difference, 10-15\%) and better postprandial blood glucose. ${ }^{50,51}$ Also in the $4 \mathrm{~T}$ trial, although not specifically designed to compare a flexible basal-bolus with premixed regimen over 3 years of follow-up, 
the superiority of basal-bolus was confirmed. ${ }^{46}$ In contrast, a recently published substudy of the DURABLE trial ${ }^{52}$ suggests no difference between the two insulin regimens. In this trial two different premixed regimens (Lispro Mix 50/50 three times a day or Lispro Mix 75/25 twice a day) achieved similar results as basal-bolus therapy. ${ }^{52}$ However, glycemic control was poor, with $<20 \%$ of patients reaching the goal of $\mathrm{A}_{1 \mathrm{C}}<7 \%$ regardless of treatment group. Therefore, noninferiority of premixed insulin was probably the result of suboptimal treatment intensification.

Indeed, the basal-bolus approach is best suited to the "treat to target strategy," allowing for independent titration of both basal and prandial insulin to address both pre- and postprandial hyperglycemia and more flexibility. In contrast, premixed insulins (which contain fixed proportions of rapidand intermediate/long-acting insulin) are used preferentially for targeting preprandial hyperglycemia. ${ }^{53}$ Of note is that when an intensive approach is used, better glycemic control is obtained with basal-bolus with a similar (or even lower) incidence of hypoglycemia in comparison to premixed regimens. ${ }^{23,50,51}$ For these reasons, premixed insulins should be restricted only as nonintensive therapy with special caution in patients with long-standing T2DM, who are likely to be more insulin deficient and prone to hypoglycemia. ${ }^{54-56}$

\section{Human insulins versus insulin analogs}

Recently, it has been suggested that insulin analogs should not be used in place of human insulin because they do not improve glycemic control, providing only "minor" benefits in terms of reduction of hypoglycemia. ${ }^{57-59}$ This recommendation is based on the results from meta-analysis and systematic reviews showing no benefit of insulin analogs over human insulin, based on $\mathrm{A}_{1 \mathrm{C}}$ reduction. However, measuring metabolic control with only $A_{1 C}$ may be misleading. In fact, RAIAs have more favorable pharmacokinetics/pharmacodynamics profile resulting in appreciable advantages compared with regular human insulin, reflected by a higher reduction of postprandial hyperglycemia and of postabsorptive hypoglycemia. ${ }^{40}$ In addition, long-acting insulin analogs show less variability and reduction of nocturnal hypoglycemia compared with NPH insulin. ${ }^{60}$ Consequently, improvement in postprandial glycemic control along with the reduction of the incidence of hypoglycemia is likely to result in lower glycemic variability compared with human insulins. All these advantages might have significant impact on diabetes-related morbidity and mortality. Indeed, both acute and postprandial hyperglycemia ${ }^{61-65}$ and glucose variability ${ }^{65}$ might theoretically contribute to the development/progression of micro- and macroangiopathic complications and incidence of cardiovascular events. In particular, a plethora of data from basic science ${ }^{65}$ have shown that fluctuating glucose activates the pathways involved in the pathogenesis of diabetes complications. On the other hand, retrospective analysis of data from large clinical trials seems to rule out an independent role of glycemic variability ${ }^{66}$ in clinical outcomes of people with diabetes. Unfortunately, this apparent contrast between basic science and clinical data will remain unsolved until intervention trials aimed at reducing glucose variability demonstrate (or exclude) a reduction in the risk of diabetes complications. However, while waiting for an answer that may never come, should we take care of glycemic vari- ability? It is our opinion that yes, we should. Indeed, addressing variability probably allows for the reduction of the incidence of hypoglycemia, ${ }^{67}$ the main complication of diabetes treatment.

Results from the ACCORD and VADT studies have recently emphasized the relationship between adverse outcomes in T2DM and hypoglycemia, especially severe hypoglycemia. ${ }^{68,69}$ Although this issue is neglected by some authors, ${ }^{70}$ others underlined how relevant this issue is in T2DM patients, ${ }^{71}$ increasing in frequency with progression of the $\beta$-cell defect and impairment of hypoglycemia counterregulation. ${ }^{72}$ In this context, the irrational use of insulin may lead to unnecessary increment in the rate of hypoglycemia with potentially fatal adverse events, especially in the frail elderly, who are rarely included in clinical trials. ${ }^{55}$ Therefore, because of its better performance and safety profile compared with human insulin, the combined use of BI and RAIAs may contribute to improvement in the care of diabetes patients. However, long-term trials are needed to find out if the abovementioned improvements in glucose control lead to improved clinical outcomes.

\section{Conclusions}

Progressive deterioration of $\beta$-cell function in people with T2DM is responsible for the initiation of insulin therapy when OAs are not enough to achieve or maintain individual glycemic goals. Addition of BI to previous OAs is the simplest way to start insulin therapy in these patients. If this approach is insufficient, adding prandial insulin is necessary over time. Recently, the basal plus therapy (i.e., a stepwise introduction of prandial insulin beginning with the main meal) has been accepted as an effective and safe alternative to premixed insulin. Additionally, this strategy will help patients if necessary in the transition to basal-bolus therapy, which remain the most effective and flexible insulin therapy even for people with T2DM.

\section{Author Disclosure Statement}

F.J.A.-B. has received honoraria as speaker and/or consultant from Abbott, AstraZeneca, Bristol-Myers Squibb, Glaxo-SmithKline, LifeScan, Lilly, Madaus, MannKind Corp., Medtronic, Menarini, Merch Farma y Química, SA, MSD, Novartis, Novo Nordisk, Pfizer, Roche, sanofi-aventis, Schering-Plough, and Solvay. In addition, F.J.A.-B. has participated in clinical trials supported totally or partially by AstraZeneca, Glaxo-SmithKline, LifeScan, Lilly, MSD, Novo Nordisk, Pfizer, sanofi-aventis, and Servier. P.R. has no potential conflicts of interest to declare. J.F.A. has received honoraria as speaker and/or consultant form AstraZeneca, Ferrer, Glaxo-SmithKline, Laboratorios Dr. Esteve, Lilly, MSD, and Solvay.

\section{References}

1. UK Prospective Diabetes Study (UKPDS) Group. UK Prospective Diabetes Study 16. Overview of 6 years' therapy of type II diabetes: a progressive disease. Diabetes 1995;44: 1249-1258.

2. Turner RC, Cull CA, Frighi V, Holman RR: Glycemic control with diet, sulfonylurea, metformin, or insulin in patients with type 2 diabetes mellitus: progressive requirement for multiple therapies (UKPDS 49). JAMA 1999;281:2005-2012. 
3. Diabetes Control and Complications Trial Research Group: The effect of intensive treatment of diabetes on the development and progression of long-term complications in insulin-dependent diabetes mellitus. N Engl J Med 1993; 329:977-986.

4. UK Prospective Diabetes Study (UKPDS) Group: Intensive blood glucose control with sulphonylureas or insulin compared with conventional treatment and risk of complications in patients with type 2 diabetes (UKPDS 33). Lancet 1998;352:837-853.

5. Ohkubo Y, Kishikawa H, Araki E, Miyata T, Isami S, Motoyosyi S, Kojima Y, Furuyoshi N, Shichiri M: Intensive insulin therapy prevents the progression of diabetic microvascular complications in Japanese patients with non-insulin-dependent diabetes mellitus: a randomized prospective 6-year study. Diabetes Res Clin Pract 1995;28: 103-117.

6. Riddle MC: Making the transition from oral to insulin therapy. Am J Med 2005;118(Suppl 5A):14S-20S.

7. Hoerger TJ, Segel JE, Gregg EW, Saaddine JB: Is glycemic control improving in U.S. adults? Diabetes Care 2008;31:81-86.

8. Yki-Järvinen H, Kauppila M, Kujansuu E, Lahti J, Marjanen R, Niskanen L, Rajala S, Ryysy L, Salo S, Seppälä P, Tulokas T, Viikari J, Karjalainen J, Taskinen M-J: Comparison of insulin regimens in patients with noninsulin-dependent diabetes mellitus. N Engl J Med 1992;327:1426-1433.

9. Riddle MC, Rosenstock J, Gerich J; Insulin Glargine 4002 Study investigators: The Treat-to-Target Trial: Randomized addition of glargine or human NPH insulin to oral therapy of type 2 diabetic patients. Diabetes Care 2003;26:3080-3086.

10. Hermansen K, Davies M, Derenzinski T, Martinez Ravn G, Clauson P, Home P: A 26-week, randomized, parallel, treatto-target trial comparing insulin detemir with $\mathrm{NPH}$ insulin as add-on therapy to oral glucose-lowering drugs in insulinnaïve people with type 2 diabetes. Diabetes Care 2006;29:1269-1274. Erratum in: Diabetes Care 2007;30:1035.

11. Nathan DM, Buse JB, Davidson MB, Ferrannini E, Holman RR, Sherwin R, Zinman B: Medical management of hyperglycemia in type 2 diabetes: a consensus algorithm for the initiation and adjustment of therapy. A consensus statement of the American Diabetes Association and the European Association for the Study of Diabetes. Diabetes Care 2009; 32:193-203.

12. Rosenstock J, Davies M, Home PD, Larsen J, Koenen C, Schernthaner G: A randomized, 52-week, treat-to-target trial comparing insulin detemir with insulin glargine when administered as add-on to glucose-lowering drugs in insulin-naive people with type 2 diabetes. Diabetologia 2008;51:408-416.

13. Schreiber SA, Ferlinz K, Haak T: The long-term efficacy of insulin glargine plus oral antidiabetic agents in a 32-month observational study of everyday clinical practice. Diabetes Technol Ther 2008;10:121-127.

14. Buse JB, Bergenstal RM, Glass LC, Heilmann CR, Lewis MS, Kwan AYM, Hoogwerf BJ, Rosenstock J: Use of twice-daily exenatide in basal insulin-treated patients with type 2 diabetes. Ann Intern Med 2011;154:103-112.

15. Arnolds S, Dellweg S, Clair J, Dain M-P, Nauck MA, Rave K, Kapitza C: Further improvement in postprandial glucose control with addition of exenatide or sitagliptin to combination therapy with insulin glargine and metformin. Diabetes Care 2010;33:1509-1515.

16. Bretzel RG, Nuber U, Landgraf W, Owens DR, Bradley C, Linn T: Once-daily basal insulin glargine versus thrice-daily prandial insulin lispro in people with type 2 diabetes on oral hypoglycaemic agents (APOLLO): an open randomised controlled trial. Lancet 2008;371:1073-1084.

17. Holman RR, Thorne KI, Farmer AJ, Davies MJ, Keenan JF, Paul S, Levy JC; 4-T Study Group: Addition of biphasic, prandial, or basal insulin to oral therapy in type 2 diabetes. N Engl J Med 2007;357:1716-1730.

18. Raz I, Wilson PWF, Strojek K, Kowalska I, Bozikov V, Gitt AK, Jermendy G, Campaigne BN, Kerr L, Milicevic Z, Jacober SJ: Effects of prandial versus fasting glycemia on cardiovascular outcomes in type 2 diabetes: the HEART2D trial. Diabetes Care 2009;32:381-386.

19. Hammer $\mathrm{H}$, Klinge A: Patients with type 2 diabetes inadequately controlled on premixed insulin: effect of initiating insulin glargine plus oral antidiabetic agents on glycaemic control in daily practice. Int J Clin Pract 2007;61:2009-2018.

20. Janka HU, Plewe G, Riddle MC, Kliebe-Frisch C, Schweitzer MA, Yki-Järvinen H: Comparison of basal insulin added to oral agents versus twice-daily premixed insulin as initial insulin therapy for type 2 diabetes. Diabetes Care 2005;28: 254-259.

21. Raskin P, Allen E, Hollander P, Lewin A, Gabbay RA, Hu P, Bode B, Garber A; INITIATE Study Group: Initiating insulin therapy in type 2 diabetes: a comparison of biphasic and basal insulin analogs. Diabetes Care 2005;28:260-265.

22. Bergenstal RM, Johnson M, Powers MA, Wynne A, Vlajnic A, Hollander P, Rendell M: Adjust to target in type 2 diabetes: comparison of a simple algorithm with carbohydrate counting for adjustment of mealtime insulin glulisine. Diabetes Care 2008;31:1305-1310.

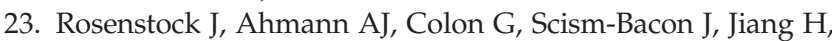
Martin S: Advancing insulin therapy in type 2 diabetes previously treated with glargine plus oral agents. Prandial premixed (insulin lispro protamine suspension/lispro) versus basal/bolus (glargine/lispro) therapy. Diabetes Care 2008;31:20-25.

24. Raccah D, Bretzel RG, Owens D, Riddle M: When basal insulin therapy in type 2 diabetes mellitus is not enoughwhat next? Diabetes Metab Res Rev 2007;23:257-264.

25. Owens DR, van Schalkwyk C, Smith P, Beer S, Goenka N, Bain SC, Bootle S, Robertson D, Robinson A, Shaw JAM: Algorithm for the introduction of rapid-acting insulin analogues in patients with type 2 diabetes on basal insulin therapy. Practical Diabetes Int 2009;26:70-77.

26. Merchante Alfaro A, García Soidán J, Alvárez Guisasola F, Bianchi Llave JL, Carral San Laureano F, Checa Zornosa P, Losada Viñau F, Marco A, Pérez Lázaro A, Pérez-Maraver M, Yoldi Arrieta A, Zafón Llopis C, Ampudia-Blasco FJ: Documento de expertos. Implementación de la estrategia basal plus en la práctica clínica. Av Diabetol 2010;26:339_ 346.

27. Monnier L, Lapinski H, Colette C: Contributions of fasting and postprandial plasma glucose increments to the overall diurnal hyperglycemia of type 2 diabetic patients: variations with increasing levels of $\mathrm{HbA}_{1 \mathrm{c}}$. Diabetes Care 2003;26:881885.

28. Monnier L, Colette C, Dunseath GJ, Owens DR: The loss of postprandial glycemic control precedes stepwise deterioration of fasting with worsening diabetes. Diabetes Care 2007; 30:263-269.

29. Riddle M, Umpierrez G, Digenio A, Zhou R, Rosenstock J: Challenging the "Monnier Concept": high basal (not postprandial) glucose dominates hyperglycemic exposure over a wide range of $\mathrm{A} 1 \mathrm{C}$ on oral therapy, and contributes 
significantly even after addition of basal insulin []abstract]. Diabetes 2010;59(Suppl 1):A171.

30. Owens DR, Sert-Langeron C, Riddle M: Adding a single dose of insulin glulisine to basal insulin glargine plus oral antihyperglycemic drug therapy improves glycemic control in type 2 diabetes: a 6-month proof of concept study [abstract]. Diabetes 2009;58(Suppl 1):A122.

31. Lankisch M, Ferlinz K, Scherbaum WA; OPAL Study Group: Basal insulin and oral antidiabetic therapy (BOT) plus a single dose of insulin glulisine $(\mathrm{BOT}+$ ) reduces $\mathrm{HbA} 1 \mathrm{c}$ and blood glucose values in patients with type 2 diabetes. Diabetes Obes Metab 2008;10:1178-1185.

32. Del Prato S, Nicolucci A, Vespasiani G: Optimising basal plus insulin therapy in type 2 diabetes by telecare assistance for self-monitoring of blood glucose- the ELEONOR study. Diabetologia 2008;51(Suppl 1):S452-S453.

33. Davidson MB, Raskin P, Tanenberg R, Vlajnic A, Hollander P: Effects of 1, 2 or 3 prandial injections of insulin glulisine on glycemic control in type 2 diabetes patients on insulin glargine and oral drugs [abstract]. Diabetes 2009;58(Suppl 1):A132.

34. Hermansen K, Kumar S, Mersebach H, Svendsen AL, Meneghini L: The STEPwise ${ }^{\mathrm{TM}}$ randomised, controlled, 48-week trial: intensifying treatment with stepwise addition of prandial insulin aspart, based on largest prandial glucose increment or largest meal, to once-daily basal insulin detemir in subjects with type 2 diabetes [abstract]. Diabetologia 2010;53(Suppl 1):S381-S382.

35. Raccah D, Haak T, Huet D, Monnier L, Ramon JS, Robertson D, Labard P, Penfornis A, OSIRIS Study Group: Stepwise intensification of prandial insulin versus basal-bolus insulin therapy in patients with type 2 diabetes mellitus [abstract]. Diabetologia 2010;53:S382.

36. Monnier L, Colette C: Addition of rapid-acting insulin to basal insulin therapy in type 2 diabetes: indications and modalities. Diabetes Metab 2006;32:7-13.

37. IDF Clinical Guidelines Task Force: Global guideline for type 2 diabetes: recommendations for standard, comprehensive, and minimal care. Diabet Med 2006;23:579-593.

38. Rodbard HW, Blonde L, Braithwaite SS, Brett EM, Cobin RH, Handelsman U, Hellman R, Jellinger PS, Jovanovic LG, Levy P, Mechanick JI, Zangeneh F; AACE Diabetes Mellitus Clinical Practice Guidelines Task Force: American Association of Clinical Endocrinologists medical guidelines for clinical practice for the management of diabetes mellitus. Endocr Pract 2007;13:1-68. Erratum in: Endocr Pract 2008; 14:802-803.

39. Hirsch IB, Bergenstal RM, Parkin CG, Wright E Jr, Buse JB: A real-world approach to insulin therapy in primary care practice. Clin Diabetes 2005;23:78-86.

40. Hirsch IB: Insulin analogues. $\mathrm{N}$ Engl J Med 2005;352: 174-183.

41. Swinnen SG, Dain M-P, Mauricio D, DeVries JH, Hoekstra JB, Holleman F: Continuation versus discontinuation of insulin secretagogues when initiating insulin in type 2 diabetes. Diabetes Obes Metab 2010;12:923-925.

42. National Institute for Health and Clinical Excellence. Type 2 Diabetes. The Management of Type 2 Diabetes. 2009. www.nice.org.uk/CG87quickrefguide (accessed February 2011).

43. Ampudia-Blasco FJ, Rosenstock J: Estrategias de insulinización en la diabetes mellitus tipo 2. Av Diabetol 2008;24:7-20.

44. Wright A, Burden AC, Paisey RB, Cull CA, Holman RR; UK Prospective Diabetes Study (UKPDS) Group: Sulfonylurea inadequacy: efficacy of addition of insulin over 6 years in patients with type 2 diabetes in the U.K. Prospective Diabetes Study (UKPDS 57). Diabetes Care 2002;25:330-336.

45. Shichiri M, Kishikawa H, Ohkubo Y, Wake N: Long-term results of the Kumamoto Study on optimal diabetes control in type 2 diabetic patients. Diabetes Care 2000;23(Suppl 2):B21-B29.

46. Holman RR, Farmer AJ, Davies MJ, Levy JC, Darbyshire JL, Keenan JF, Paul SK; 4-T Study Group: Three-year efficacy of complex insulin regimens in type 2 diabetes. $\mathrm{N}$ Engl J Med 2009; 361:1736-1747. Erratum in: N Engl J Med 2010;363: 2078.

47. Lasserson DS, Glasziou P, Perera R, Holman RR, Farmer AJ: Optimal insulin regimens in type 2 diabetes mellitus: systematic review and meta-analyses. Diabetologia 2009;52: 1990-2000.

48. Giugliano D, Maiorino MI, Bellastella G, Chiodini P, Esposito K: Treatment regimens with insulin analogues and haemoglobin A1c target of $<7 \%$ in type 2 diabetes: a systematic review. Diabetes Res Clin Pract 2010; Sep 3 [Epub ahead of print]. doi: 10.1016/j.diabres.2010.08.006.

49. Hollander P, Cooper J, Bregnhøj J, Pedersen CB: A 52-week, multinational, open-label, parallel-group, noninferiority, treat-to-target trial comparing insulin detemir with insulin glargine in a basal-bolus regimen with mealtime insulin aspart in patients with type 2 diabetes. Clin Ther 2008;30: 1976-1987.

50. Liebl A, Prager R, Binz K, Kaiser M, Bergenstal R, Gallwitz B; PREFER Study Group: Comparison of insulin analogue regimens in people with type 2 diabetes mellitus in the PREFER Study: a randomized controlled trial. Diabetes Obes Metab 2009;11:45-52.

51. Fritsche A, Larbig M, Owens D, Häring H-U; GINGER Study Group: Comparison between a basal-bolus and a premixed insulin regimen in individuals with type 2 diabetes-results of the GINGER study. Diabetes Obes Metab 2010;12:115-123.

52. Miser WF, Arakaki R, Jiang H, Scism-Bacon J, Anderson PW, Fahrbach JL: Randomized, open-label, parallel-group evaluations of basal-bolus therapy versus insulin lispro premixed therapy in patients with type 2 diabetes mellitus failing to achieve control with starter insulin treatment and continuing oral antihyperglycemic drugs: a noninferiority intensification substudy of the DURABLE trial. Clin Ther 2010;32:896-908.

53. Unnikrishnan AG, Tibaldi J, Hadley-Brown M, Krentz AJ, Ligthelm R, Damci T, Gumprecht J, Gero L, Mu Y, Raz I: Practical guidance on intensification of insulin therapy with BIAsp 30: a consensus statement. Int J Clin Pract 2009;63: 1571-1577.

54. Henderson JN, Allen KV, Deary IJ, Frier BM: Hypoglycaemia in insulin-treated Type 2 diabetes: frequency, symptoms and impaired awareness. Diabet Med 2003;20:1016-1021.

55. Donnelly LA, Morris AD, Frier BM, Ellis JD, Donnan PT, Durrant R, Band MM, Reekie G, Leese GP; DARTS/MEMO Collaboration: Frequency and predictors of hypoglycaemia in Type 1 and insulin-treated Type 2 diabetes: a populationbased study. Diabet Med 2005;22:749-755.

56. Akram K, Pedersen-Bjergaard U, Carstensen B, BorchJohnsen K, Thorsteinsson B: Frequency and risk factors of severe hypoglycaemia in insulin-treated Type 2 diabetes: a cross-sectional survey. Diabet Med 2006;23:750-756.

57. Siebenhofer A, Plank J, Berghold A, Jeitler K, Horvath K, Narath M, Gfrerer R, Pieber TR: Short acting insulin analogues 
versus regular human insulin in patients with diabetes mellitus. Cochrane Database Syst Rev 2006;(2):CD003287.

58. Horvath K, Jeitler K, Berghold A, Ebrahim SH, Gratzer TW, Plank J, Kaiser T, Pieber TR, Siebenhofer A: Long-acting insulin analogues versus NPH insulin (human isophane insulin) for type 2 diabetes mellitus. Cochrane Database Syst Rev 2007;(2):CD005613.

59. Holleman F, Gale EA: Nice insulins, pity about the evidence. Diabetologia 2007;50:1783-1790.

60. Rossetti P, Porcellati F, Fanelli C, Perriello G, Torlone E, Bolli GB: Superiority of insulin analogues versus human insulin in the treatment of diabetes mellitus. Arch Physiol Biochem 2008;114:3-10.

61. The DECODE Study Group, the European Diabetes Epidemiology Group: Glucose tolerance and cardiovascular mortality: comparison of fasting and 2-hour diagnostic criteria. Arch Intern Med 2001;161:397-405.

62. Meigs JB, Nathan DM, D'Agostino RB Sr, Wilson PW; Framingham Offspring Study: Fasting and postchallenge glycemia and cardiovascular disease risk: the Framingham Offspring Study. Diabetes Care 2002;25:1845-1850.

63. Chiasson JL, Josse RG, Gomis R, Hanefeld M, Karasik A, Laakso M; STOP-NIDDM Trial Research Group: Acarbose treatment and the risk of cardiovascular disease and hypertension in patients with impaired glucose tolerance: the STOP-NIDDM trial. JAMA 2003;290:486-494.

64. Gresele P, Guglielmini G, De Angeles M, Ciferri S, Ciofetta M, Falcinelli E, Lalli C, Ciabattoni G, Davì G, Bolli GB: Acute, short-term hyperglycemia enhances shear stressinduced platelet activation in patients with type II diabetes mellitus. J Am Coll Cardiol 2003;41:1013-1020.

65. Ceriello A, Ihnat MA: 'Glycaemic variability': a new therapeutic challenge in diabetes and the critical care setting. Diabet Med 2010;27:862-867.

66. Kilpatrick ES, Rigby AS, Atkin SL: For debate. Glucose variability and diabetes complication risk: we need to know the answer. Diabet Med 2010;27:868-871.

67. Kilpatrick ES, Rigby AS, Goode K, Atkin SL: Relating mean blood glucose and glucose variability to the risk of multiple episodes of hypoglycaemia in type 1 diabetes. Diabetologia 2007;50:2553-2561.
68. Duckworth W, Abraira C, Moritz T, Reda D, Emanuele N, Reaven PD, Zieve FJ, Marks J, Davis SN, Hayward R, Warren SR, Goldman S, McCarren M, Vitek ME, Henderson WG, Huang GD; VADT Investigators: Glucose control and vascular complications in veterans with type 2 diabetes. $\underline{\mathrm{N}}$ Engl J Med 2009;360:129-139. Erratum in: N Engl J Med 2009;361:1028.

69. Bonds DE, Miller ME, Bergenstal RM, Buse JB, Byington RP, Cutler JA, Dudl RJ, Ismail-Beigi F, Kimel AR, Hoogwerf B, Horowitz KR, Savage PJ, Seaquist ER, Simmons DL, Sivitz WI, Speril-Hillen JM, Sweeney ME: The association between symptomatic, severe hypoglycaemia and mortality in type 2 diabetes: retrospective epidemiological analysis of the ACCORD study. BMJ 2010;340:b4909. doi: 10.1136/bmj.b4909.

70. Nathan DM, Buse JB, Davidson MB, Heine RJ, Holman RR, Sherwin R, Zinman B: Management of hyperglycemia in type 2 diabetes: a consensus algorithm for the initiation and adjustment of therapy. A consensus statement from the American Diabetes Association and the European Association for the Study of Diabetes. Diabetes Care 2006;29:1963-1972. Erratum in Diabetes Care 2006;49:28162818.

71. Cryer PE: Management of hyperglycemia in type 2 diabetes: a consensus algorithm for the initiation and adjustment of therapy: a consensus statement from the American Diabetes Association and the European Association for the Study of Diabetes. Diabetes Care 2007;30:190-192.

72. Segel SA, Paramore DS, Cryer PE: Hypoglycemia-associated autonomic failure in advanced type 2 diabetes. Diabetes 2002;51:724-733.

Address correspondence to: F. Javier Ampudia-Blasco, M.D. Diabetes Reference Unit Endocrinology and Nutrition Department Clinic University Hospital of Valencia Avda. Blasco Ibáñez 17 46010 Valencia, Spain

E-mail: Francisco.J.Ampudia@uv.es 

This article has been cited by:

1. Satish K. Garg , Emily G. Moser . 2011. How Basal Insulin Analogs Have Changed Diabetes CareHow Basal Insulin Analogs Have Changed Diabetes Care. Diabetes Technology Therapeutics 13:S1, S-1-S-4. [Citation] [Full Text] [PDF] [PDF Plus] 